\title{
The Application of Chinese Traditional Decorative Elements in Public Space
}

\author{
Lu Cheng ${ }^{1}$, Ge Cheng ${ }^{2}$ \\ ${ }^{1} 1$ ShangHai Publishing and Printing College, China \\ ${ }^{2}$ Shanghai Sibo vocational and Technical College, China
}

Keywords: Traditional, Modern, Essence, Element, Nature, Innovation.

\begin{abstract}
Chinese traditional culture and traditional arts are decorated and decorated, they are the source of inspiration for creating a new era and a new atmosphere in modern public space. Designers will traditional elements, symbols, folk customs of life, Different materials are applied to the design of public space, in a modern abstract form, and modern space is a commitment to the past and the future, Create urban public space of old and new symbiosis by traditional and fashionable techniques.
\end{abstract}

\section{Introduction}

China is an ancient country with a long tradition and history, Chinese traditional culture, traditional arts and crafts, decoration, Are the source of inspiration for our public space design. Designers will be traditional styling, folk customs of life, Different materials and other factors are applied to the space design to be deformed and abstract, and the traditional and fashionable techniques are used to create a new and symbiotic public space.

\section{The first ten years of Chinese public space art design}

All kinds of decorative elements are completely mechanically to the public space, such as the last passenger station waiting room, for large wall decoration of the station, with the characteristics of the local ethnic painting materials and painting language,Directly on the wall as a space decoration, to show the characteristics of regional culture, of course, this is the era of artistic development and regional culture of the performance of the country, subject to social development constraints, it seems a bit stiff.Chinese traditional decoration is rooted in the traditional culture Chinese, contains the surface related to the life custom, all aspects of construction, embodies the China farming culture under the patriarchal system and the Confucian ethics and aesthetic theory, While the modern public space design emphasizes the cultural historical and regional characteristics, focusing on Coordination era and human society and environment, and the unity of function and structure, and the combination of technology and art, and focus on the local characteristics and personality. With the development of social times, the structure, form, material and living environment of architecture have undergone epoch-making changes,From farming to civil electronic steel and glass curtain wall structure form, concrete folk native LCD screen to the electronic element in the past today, all the elements are no longer caught in the traditional solid performance, how to put the modern thought and traditional culture combine performance style of the times, how to combine the natural ecological concept and modern indifference structure,How to combine the natural ecological concept and modern indifferent structure, how the traditional culture elements rooted in expression of humanism in modern design and inheritance of warm hardening abstract, are exploring ways to use the traditional elements in modern public space. There are not many designs about how to combine the local culture, the regional customs and the new era,Many of the design in order to reflect the culture of some elements of traditional ornament blindly piling, not the science and deep vein scrutiny, or context in modern international style without an increase in traditional elements, people do not take the side of the tough to accept cultural aggression, are totally deviated from the aesthetic tradition in the era of the application.For example, the past is the queen of the glazed tile building material aristocratic palace, is a symbol of the level of performance, by 80s and 90s, simplified and glazed tile with classical 
architectural style has gradually become a symbol of luxury hotel performance, has become a high-grade materials for space use, glazed tile is the specific material in a particular location of the building the traditional culture symbol meaning it did not extend and abstract stripped to the modern, glazed tile has become a decorative symbol, is no longer the use of a building tile material, It became a reproduction of cultural connotation: the meaning of gold rich translucent classical decorative symbols and so on unique, applied to the outside of the building and interior a position, to show people a golden luxury or a rich fantasy. Even in the modern decoration to enjoy light background, more active the spatial culture connotation, interpretation of the new times.

Liu Jiakun designed the Luyeyuan Stone Sculpture Museum, is a traditional decorative elements and modern public space with the most classic design example is efforts to continuously explore the architect designer for twenty years, the museum collections in stone as the theme, the building located in the flood plain, the entire building and landscape with no decoration and elegant plain texture the concrete and brick for large surface design, structure and layout for the exhibition hall around the atrium, light way using the building block space organization atmosphere, with natural bamboo separate and connect regional space, The clever use of various forms of water movement to add smart atmosphere and artistic conception of Zen, which created the exhibits. The building is modern, form and language is modern, the interior space with the traditional decorative elements such as water, lighting off a statue of Buddha carved stone, the entire building presents the history and modern collision, and soft and cold, light and texture interactive tension, the whole atmosphere is traditional,Like the traditional elements of omnipresent, lines of light material atmosphere, but carefully identify and modern lines: light texture, the traditional elements to simplify Abstract everywhere and fusion hidden, unable to say the atmosphere, will be exposed, using natural materials, the most common wall of modern technology and low processing with nature. The atmosphere of the work is restrained and the time, space, culture, tradition and the future are all integrated and displayed. It gives a good connection between the past and the future.

In classical gardens, many China traditional decorative elements have demonstrated their unique decorative features and cultural connotation, not only has the unity of nature and the landscape garden building, floor in the garden also plays an important role and decorative meaning. Pomegranate peach blossom of Chinese elements full of good moral assembly to decoration, across the garden everywhere, besides practical function also has the symbolic significance.Now the garden has become open to the public, public space, all kinds of traditional decorative elements such as red flower lantern wooden hollow flower window ceramics, is no longer a necessary factor, but a symbol of a simplified abstract space for ornament or a cultural element, is not part of a rich space, but a a cultural symbol of the modern era, such as the floor decoration, floor has most of the concrete, Qingshiban modern fired clay brick, The imitation of natural marble and granite material and so on, instead of pebbles tile pieces, with a modern language form in some pavement, the garden path follows the floor of the classical garden, only retain the beauty of form elements, abandoned a national symbol of meaning, but the elements are used in some public space of culture the building, with a building texture silent to express his meaning and cultural heritage, from the plane to the vertical space symbols or texture display, Therefore, how to use the traditional decorative elements, how to inherit the traditional culture and develop new era characteristics, is the focus of the traditional culture in the design of public space. Another example is Suzhou's most distinctive hollow flower window, spread everywhere in Suzhou since modern buildings and fences, everyone realized that it became a symbol of the use, just a place that is now handling the design of public space in Suzhou, is the use of modern design to use this kind of cultural symbol, such as a wall on the wall is no longer the size of flower window, but increase in size as part of the wall is the wall, and texture patterns, or use a small part of it as an embellishment, so that the wall surface becomes small, the window is a point, with modern design language has become a modern form, is no longer a heavy cultural symbol but, I think it is the continuation of traditional culture to the abstract.

\section{The application of Suzhou classical garden art elements in modern garden}

In order to protect the ancient city of Suzhou in the past on the construction of the metro, the 
garden of the various elements of mechanically design to residential streets public space in city park. This is the appearance of understanding of the essence of culture, did not show the characteristics of Suzhou natural cultural heritage on the basis of the future new spirit of the Wanxiu in new era. How to seize the soul to express its essence is the essence of cultural tradition elements applied to modern space design. First of China classical garden history, cultural connotation, aesthetic orientation and creative means of analysis, find out the design principles of natural law is a fundamental principle of the classical gardening creation method, the overall layout of the principle for China re shaping of public space and aesthetic taste has played a decisive role. It is also the guiding principle of how to reproduce cultural symbols on the basis of today's urban public space design. Donald once proposed three aspects of modern garden design: function, empathy and aesthetics, which are also a principle in public space, so the traditional elements are not merely as decorations of architecture. Not only should we pay attention to the performance of aesthetics, but also the cultural annotation of society and city. Thus become the direction of the use of traditional elements in the design of public space.

The most successful case in Suzhou is the design of Li Gongdi's public space on Jinji lake. It's 1400 meters long. The successful completion of the ancient people in the water side of water and stone on the prosperity of the town through the misty temperament show use nowadays means of interpretation. If the dream can then glimpse of merchants in modern neon lights under the pomp. $\mathrm{Li}$ Gongdi according to the overall space requirements, guided by the theories of ecology to absorb the essence of Chinese classical garden layout, simplify the structure of classical wooden frame, pavilions, terraces and open halls, simplified stone ladder, an arched stone bridge in the water elevation and presents classical spirit.

\section{The application of classical elements in modern landscape design}

The use of modern materials and construction, modern architectural elements and modern lighting contrast, combination of classical and modern elements form space, in order to create a modern space in a simple and natural green and classical culture of the culture and entertainment space, rich local culture, the continuation of the historical context. Considering the needs of the geographical environment and the function of the place, we should draw lessons from the coordination of the plant techniques of the classical garden and the overall landscape environment. Refined garden of Suzhou cloth, the natural combination of cultural elements of a quality suggestive of poetry or painting artistic conception, in the natural style, the Li Gongdi is a reality and fantasy in ancient interwoven scenes, ancient elements in Water Pavilion Taiwan and the integration of modern elements, the people on the water and water on the street facade of prosperity show temperament extends to the entire golden rooster the lake, the Jinji Lake full of bustling Suzhou and poetic atmosphere dream, but with the surrounding modern architectural environment set off each other. For us to build a universe of time intertwined modern public space.

In the current construction of rural urbanization in the country, blindly pushed all the people's livelihood construction of classical architecture or denying the original village construction of rural landscape, leading to destruction of the ecological environment of the town, the structure of town chaos, the disappearance of local characteristics and a series of serious problems. Especially the construction of rural urbanization has been a thousand times the same color. China town development machine-made too, how to keep their traditional features, how to use the geographical characteristics of the traditional elements to develop local cultural characteristics, how to use their own cultural features in the small town construction in the unique characteristics of modern economic development, tourism development of its own characteristics of the public space is the future direction of the town.

On the other hand, people are increasingly aware of the importance of ecological environment construction, desire into the natural, cultural environment, psychological pressure between the release of people increasingly tired people to well-off process and the development of science and technology in life at the same time, an increase in leisure time, more eager to meet the health and leisure life space, just in front of several parks and green spaces can not meet the needs of the public. In the trend of economic development, resulting in various design all kinds of cultural symbols by 
mutual rubbing behavior abnormalities, this is the culture understanding, is the deliberate retention of traditional decoration, is forced to inherit the national culture, is the public space of the appearance of a superficial design overbearing.There are always some unique symbols and permutations in public space. Like a dialect, cleverly infused into the dialect. To strengthen the sense of continuous space history and local flavor, such as some traditional practices or China, there are a lot of art symbol in prototype. Change the material and change the function. Tile "wave" detail, and stainless steel and two kinds of materials, coarse and thin contrast, forming a strong contrast. In the material, the modern landscape materials and traditional Chinese materials fusion. Not only China's traditional, cultural, material, customs and so on, but also modern materials, glass, steel structure, stainless steel texture, texture and feel, and so on.For example, in the new campus of Shenyang Construction University, northeast rice was used as the main symbol of public space, and a campus rice field was designed. With the most common and most economical and productive materials, in a contemporary campus, the interpretation of the importance of land, farming situation in the university culture, the interpretation of the "vernacular" space concept and extension of thinking, China agricultural culture has been re display and attention, the artistic conception of different fields in the traditional China. It is the importance of agricultural culture and agricultural cultivation in China. It is an idyllic scene. It has produced an important source of ideological science and technology in the cultural palace,Is a simple manifestation of the pursuit of a new era of origin, clever and become the main elements of public space landscape, a traditional crop Chinese from growth to Golden Harvest space has become a modern form of symbols of the public space, this is the successful performance of modern design. The use and creation of symbols must be accurate and appropriate. They should be unified and integrated with other molding factors. Symbols can be works of art, or objects, but also plants, stones, water..... Creative designers can change meaningful things in life into visual symbols. Applying the elements of traditional ornament to the modern space in artistic creation, we use the symbol way, in the image of simplification, deformation, abstract; in the aspect of material of new materials, new technology and texture; in the space of the back scattered combination, make the traditional decorative elements of the original retained some essence the characteristics, into a new vision symbol.

\section{Conclusion}

Finally, the relationship between inheritance and innovation. The modern public space design and creation, we also find the imitation of the design principle of nature, is also a public space design basis and the essence of the theory, in order to seek development with public space design Chinese national innovation road. Citing past history Tsinghua professor Zhou Weiquan's words "human society shows that in the new culture changed rapidly, if not to break the old cultural rule," traditional "will become a burden, to strengthen their closeness and exclusivity. Once the shackles of old culture are broken and the new cultural system is established, then the tradition can be of new significance in this system and become a wealth that can be used for reference or even partially inherited. The essence of the problem lies in the understanding of traditional culture and history, we must recognize the era of cultural tide, will know how to protect her, and in her development, material and technical level, has a heritage and confidence on the spirit and culture. Only when we recognize the fusion of nature, modern culture and science, we will know more how to learn his design thinking, master his methods and techniques, and better demonstrate the features of modern China's public space. People pay more and more attention to the significance of social ecology and culture in public space, and pay more and more attention to the influence of the world's aesthetic philosophy on the concept of modern public space.

\section{References}

[1] Matei Calinescu, "the five faces of modernity", Beijing University Press, 2002, p.341.

[2] Wang Xiaoming, the opening and preface of critical space. See "the creation of critical space - 
Chinese literature research in twentieth Century", edited by Wang Xiaoming, Shanghai, Oriental publishing center, 1998, p.11.

[3] "The creation of critical space - Chinese literature research in twentieth Century", edited by Wang Xiaoming, Shanghai, Oriental publishing center, 1998, pp.38, 39.

[4] Indigenous landscape network Yu Kongjian's design theory http://www. turenscape. com/ home. php

[5] "Art concept, landscape process - art creation approach to landscape design" and its significance. Liao Shengan, master's thesis, School of architecture, China Central Academy of Fine Arts, 2005

[6] "Western" theory and practice of modern landscape design Wang Xiangrong Lin Beijing: China Architectural Industry Press, 2002, 7.

[7] A hundred years' review of the value of Western landscape architecture. Doctoral dissertation of Tang Jun, Nanjing: Southeast University press, 2004. 